\title{
Target-Specific Neuropeptide Y-Ergic Synaptic Inhibition and Its Network Consequences within the Mammalian Thalamus
}

\author{
Qian-Quan Sun, ${ }^{1}$ Scott C. Baraban, ${ }^{2}$ David A. Prince, ${ }^{1}$ and John R. Huguenard ${ }^{1}$ \\ ${ }^{1}$ Department of Neurology and Neurological Sciences, Stanford School of Medicine, Stanford, California 94305, and ${ }^{2}$ Department of Neurological Surgery, \\ University of California, San Francisco, San Francisco, California 94143
}

\begin{abstract}
Neuropeptides are commonly colocalized with classical neurotransmitters, yet there is little evidence for peptidergic neurotransmission in the mammalian CNS. We performed whole-cell patch-clamp recording from rodent thalamic brain slices and repetitively stimulated corticothalamic fibers to strongly activate NPY-containing GABAergic reticular thalamic (RT) neurons. This resulted in long-lasting $(\sim 10 \mathrm{sec})$ feedforward slow IPSPs (sIPSPs) in RT cells, which were mimicked and blocked by $\mathrm{NPY}_{1}\left(\mathrm{Y}_{1}\right)$ receptor agonists and antagonists, respectively, and were present in wild-type mice but absent in NPY ${ }^{-1-}$ mice. NPYergic sIPSPs were mediated via G-proteins and G-protein-activated, inwardly rectifying potassium channels, as evidenced by sensitivity to GDP- $\beta$-S and $0.1 \mathrm{~mm} \mathrm{Ba}{ }^{2+}$. In rat RT neurons, NPYergic sIPSPs were also present but were surprisingly absent in the major synaptic targets of RT, thalamic relay neurons, where instead robust $\mathrm{GABA}_{\mathrm{B}}$ IPSPs occurred. In vitro oscillatory network responses in rat thalamus were suppressed and augmented by $\mathrm{Y}_{1}$ agonists and antagonists, respectively. These findings provide evidence for segregation of postsynaptic actions between two targets of RT cells and support a role for endogenously released NPY within RT in the regulation of oscillatory thalamic responses relevant to sleep and epilepsy.
\end{abstract}

Key words: neuropeptide Y; endogenous neuropeptide; IPSPs; GIRK channels; burst firing; oscillations

\section{Introduction}

The coexistence of neuropeptides with classical neurotransmitters in neurons has been well established in a number of studies over the last two decades (Hökfelt, 1991; Hökfelt et al., 2000). Important roles for peptide neurotransmitters have been determined, especially from studies of central pattern generators in invertebrate systems (Nusbaum et al., 2001). However, our understanding of the precise physiological roles of endogenous neuropeptides in CNS neurons is largely incomplete for the following reasons: (1) postsynaptic responses of neuropeptides tend to be small, slowly rising, and long lasting (Jan and Jan, 1982; Weisskopf et al., 1993); (2) selective antagonists for peptidergic receptors are generally unavailable (Hökfelt et al., 2000); (3) most neuropeptides cannot be detected electrochemically (Chow and von Rüden, 1995; Whim and Moss, 2001); and (4) neuropeptides are packaged in large dense-core vesicles, the release of which is restricted by limited secretory granule mobility (Burke et al., 1997). Thus, although several dozen neuropeptides have been identified (Hökfelt et al., 2000), there are very few examples showing clear functional effects of endogenously released neu-

\footnotetext{
Received May 23, 2003; revised Sept. 2, 2003; accepted Sept. 2, 2003.

This work was supported by National Institutes of Health-National Institute of Neurological Disorders and Stroke Grant NS12151 and the Pimley Research and Training Funds. We are grateful to Michael Nusbaum for critical comments on a previous version of this manuscript and to Isabel Parada for excellent technical assistance in the immunocytochemistry experiments.

Correspondence should be addressed to Dr. John R. Huguenard, Department of Neurology and Neurological Sciences, Stanford University School of Medicine, Stanford, CA 94305. E-mail: John.Huguenard@stanford.edu. Copyright $\odot 2003$ Society for Neuroscience $\quad$ 0270-6474/03/239639-11\$15.00/0
}

ropeptides on neural network activities (for review, see Nusbaum et al., 2001).

It has been proposed that actions of neuropeptides can be classified as either "neuromodulatory" or "neurotransmitter" (Strand, 1999; Hökfelt et al., 2000; Nusbaum et al., 2001). Although a variety of studies in the mammalian CNS have documented that application of exogenous neuropeptides leads to both presynaptic and postsynaptic actions, evidence has been sparse for transmission mediated via naturally released peptides. In fact, compelling evidence so far exists for only a few neuromodulatory actions (Wagner et al., 1993; Weisskopf et al., 1993; Baraban et al., 1997; Kombian et al., 1997). In addition to the above endogenous modulatory actions that influence neurotransmitter release, in a few cases, endogenously released neuropeptides have been shown to directly evoke slow EPSPs in the PNS and spinal cord (Nicoll, 1978; Jan et al., 1979; Kupfermann, 1991). As yet, there is no direct evidence for peptidergic IPSPs in the mammalian CNS.

The intrathalamic circuit has a number of potential advantages for the study of functional responses resulting from release of neuropeptides. NPY is present in the GABAergic neurons of the nucleus reticularis [reticular thalamic (RT) nucleus] (Molinari et al., 1987; Morris, 1989), and NPY receptors (particularly NPY 1 receptors) are abundantly expressed at postsynaptic sites on these cells (Molinari et al., 1987; Sun et al., 2001a,b). Reciprocal connections between inhibitory RT and excitatory relay neurons (von Krosigk et al., 1993) promote recurrent network oscillatory activity. Such oscillations are dependent on burst firing in 
reticular and relay neurons (Huguenard, 1999; McCormick and Contreras, 2001; Steriade, 2001) and can be used as a sensitive index response to detect peptidergic actions (Cox et al., 1997; Sun et al., 2002a). In the experiments reported here, we took advantage of this favorable circuitry, the availability of potent and selective $\mathrm{Y}_{1}$ antagonists (Doods et al., 1995; Sun et al., 2001b), and genetically NPY-deficient mice (Erickson et al., 1996) to provide a demonstration of peptidergic IPSPs, mediated by NPY. We show that peptidergic output of GABA/NPYergic RT neurons is segregated between recurrent and feedforward nerve terminals. Although both RT and thalamocortical (TC) neurons possess postsynaptic $\mathrm{NPY}_{1}$ receptors that are functionally coupled to G-protein-activated, inwardly rectifying potassium (GIRK) channel activation (Sun et al., 2001a,b), RT neurons preferentially use NPY at their recurrent synapses within the reticular nucleus to generate slow IPSPs (sIPSPs), whereas minimal NPYergic effects were detected at synapses on relay neurons, where instead $\mathrm{GABA}_{\mathrm{B}}$ receptor-mediated synaptic responses predominated. We also show that NPYergic feedback, presumably within RT, provides use-dependent negative feedback of network oscillations.

\section{Materials and Methods}

NPY knock-out mice. Mice deficient in NPY were generated by Erickson et al. (1996). All experiments were performed on F2 and F3 129SV/ EVJR2448 hybrid males and were performed using a protocol approved by the Stanford Institutional Animal Care and Use Committee.

Thalamic slice preparation. Young [postnatal day 12 (P12)-P16] $\mathrm{NPY}^{-1-}$ and $\mathrm{NPY}^{+/+}$mice of the same background strain (129SV/ EVJR2448) and young Sprague Dawley rats were deeply anesthetized with pentobarbital sodium $(55 \mathrm{mg} / \mathrm{kg})$ and decapitated. The brains were removed quickly and placed into cold $\left(\sim 4^{\circ} \mathrm{C}\right)$ oxygenated slicing medium. The slicing medium contained (in mM): $2.5 \mathrm{KCl}, 1.25 \mathrm{NaH}_{2} \mathrm{PO}_{4}$, $10 \mathrm{MgCl}_{2}, 0.5 \mathrm{CaCl}_{2}, 26 \mathrm{NaHCO}_{3}, 11$ glucose, and 234 sucrose. Tissue slices $(300-400 \mu \mathrm{m})$ were cut in the horizontal plane using a vibratome (TPI, St. Louis, MO), transferred to a holding chamber, and incubated $\left(35^{\circ} \mathrm{C}\right)$ for at least $1 \mathrm{hr}$ before recording. Individual slices were then transferred to a recording chamber fixed to a modified microscope stage and allowed to equilibrate for at least $30 \mathrm{~min}$ before recording. Slices were continuously superfused with oxygenated physiological saline at the rate of $4.0 \mathrm{ml} / \mathrm{min}$. The physiological perfusion solution contained (in $\mathrm{mM}$ ): $126 \mathrm{NaCl}, 2.5 \mathrm{KCl}, 1.25 \mathrm{NaH}_{2} \mathrm{PO}_{4}, 1 \mathrm{MgCl}_{2}, 2 \mathrm{CaCl}_{2}, 26 \mathrm{NaHCO}_{3}$, and 10 glucose. These solutions were gassed with $95 \% \mathrm{O}_{2} / 5 \% \mathrm{CO}_{2}$ to a final $\mathrm{pH}$ of 7.4 at a temperature of $35 \pm 1^{\circ} \mathrm{C}$.

Whole-cell patch-clamp recording. Whole-cell recordings were obtained using visualized slice patch techniques and a modified microscope (Zeiss Axioskop) with a fixed stage. A low-power objective $(2.5 \times)$ was used to identify the various thalamic nuclei, and a high-power waterimmersion objective $(40 \times)$ with Nomarski optics and infrared video was used to visualize individual neurons. Recording pipettes were fabricated from capillary glass obtained from World Precision Instruments (M1B150F-4), using a Sutter Instrument P80 puller, and had tip resistances of 2-5 M $\Omega$ when filled with the intracellular solutions below. An Axopatch1A amplifier and an AxoClamp2B amplifier (Axon Instruments, Foster City, CA) were used for voltage-clamp and current-clamp recordings, respectively. Access resistance in whole-cell recordings ranged from 4 to $12 \mathrm{M} \Omega$ and was stable ( $<25 \%$ change) during experiments. Current and voltage protocols were generated using pClamp software (Axon Instruments). Patch pipette saline was modified according to Sodickson and Bean (1996) and was composed of (in $\mathrm{mM}$ ): 100 K-gluconate, $13 \mathrm{KCl}, 9 \mathrm{MgCl}_{2}, 0.07 \mathrm{CaCl}_{2}, 10 \mathrm{EGTA}, 10 \mathrm{HEPES}, 2 \mathrm{Na}_{2}-$ ATP, and 0.4 Na-GTP, pH adjusted to 7.4, and osmolarity adjusted to $280 \operatorname{mosMl}^{-1}$. A sharpened bipolar tungsten electrode placed in the internal capsule near RT was used to deliver synaptic stimulation. To quantify sIPSPs, we measured the difference between resting membrane potential and that measured $1000 \mathrm{msec}$ after the last stimulus in the train.

Extracellular multiple-unit activities were recorded using monopolar tungsten electrodes (0.2-2 M 2 ; Frederick Haer, Brunswick, ME) and a Grass amplifier (bandwidth, $0.03-3 \mathrm{kHz})$. All data were digitized $(6 \mathrm{kHz})$ and stored using Axotape software (Axon Instruments). Extracellular stimuli were delivered to the internal capsule through bipolar sharpened tungsten electrodes. To quantify the degree of synchrony and the duration of the intrathalamic oscillations, autocorrelograms were constructed from the extracellular multiple-unit data. The oscillatory activity in the autocorrelograms was quantified by four measures: number of well-defined peaks; time constant of oscillation decay; oscillatory index (OI); and the period of oscillation (Cox et al., 1997; Huntsman et al., 1999; Sun et al., 2002a). A modified Gabor function measured distinct autocorrelogram components, including a nonoscillatory component (Rand), an exponentially decaying cosine function (Osc, with a characteristic time constant of oscillation decay), and an oscillatory period (interburst period). The OI was calculated as $(\mathrm{P}-\mathrm{V}) / \mathrm{P}$, where $\mathrm{P}$ is the amplitude of the autocorrelogram central peak, and $\mathrm{V}$ is the amplitude of its first valley.

Immunocytochemistry. Biocytin $(0.5 \%)$ was included in the pipette solution to label RT neurons during electrophysiological recordings. Brain slices were removed from the recording chamber and fixed in $4 \%$ paraformaldehyde in $0.1 \mathrm{M}$ phosphate buffer overnight and transferred to 0.1 м PBS, pH 7.4, for $10 \mathrm{hr}$. The brain slices were then sectioned at 100 $\mu \mathrm{m}$ with a vibratome. Sections were blocked in $10 \%$ normal goat serum and then incubated for $16 \mathrm{hr}$ in buffer containing rabbit NPY 1 receptor antibody (1:2000; Dia Sorin). After rinsing in PBS, the sections were incubated in a mixture of Alexa goat anti-rabbit FITC and Alexa goat anti-mouse Texas Red ( $5 \mu \mathrm{g} / \mathrm{ml}$ each; Chemicon) for $2 \mathrm{hr}$. Sections were mounted on slides and coverslipped using Vectashield mounting media (Vector Laboratories). Double immunofluorescence was assessed with a laser scanning confocal microscope (Zeiss LSM 510).

Drugs. Drugs were applied focally through a multibarrel microperfusion pipette that was positioned within $1 \mathrm{~mm}$ of the cell. Concentrated NPY, Leu ${ }^{31}$ Pro ${ }^{34}$ NPY, and BIBP3226 (Peninsula Laboratories, Belmont, $\mathrm{CA}$ ) stock solutions were dissolved in ultra-pure water to a final concentration of $0.1 \mathrm{M}$ and stored in a $-70^{\circ} \mathrm{C}$ freezer. Stock solutions were diluted in physiological saline to final concentrations of $100 \mathrm{nM}$ to $1 \mu \mathrm{M} 1$ hr before use. GDP- $\beta$-S, bicuculline methiodide (BMI), and biocytin apamin were purchased from Sigma (St. Louis, MO).

Statistics. All data are presented as means \pm SEM, unless stated otherwise. Unless indicated otherwise, statistical significance was assessed with a two-tailed Student's $t$ test. Probability values of $<0.05$ were considered statistically significant.

\section{Results}

\section{Synaptic stimulus trains elicit long-lasting IPSPs in RT} neurons from wild-type, but not NPY, knock-out mice

RT neurons receive glutamatergic corticothalamic and TC inputs (Warren and Jones, 1997; Liu and Jones, 1999) and a disynaptic feedforward inhibition from neighboring RT cells via recurrent GABAergic connections (Scheibel and Scheibel, 1996; Zhang et al., 1997; Huntsman et al., 1999) (Fig. 1A1). Thus, recordings made from RT neurons in TC or horizontal slices reveal monosynaptic AMPA receptor-mediated and NMDA receptormediated EPSPs (Warren and Jones, 1997) and disynaptic feed-

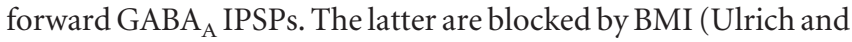
Huguenard, 1995; Kim et al., 1997; Warren and Jones, 1997). We performed whole-cell patch-clamp recordings from visually and electrophysiologically identified (Fig. 1A2) RT neurons in horizontal mouse thalamic brain slices and used $10 \mu \mathrm{M}$ BMI to block $\mathrm{GABA}_{\mathrm{A}}$-mediated recurrent IPSPs (Zhang et al., 1997; Huntsman et al., 1999) and afterhyperpolarizations (AHPs) (Debarbieux et al., 1998). Under these conditions, extracellular stimuli applied to the internal capsule evoked spike bursts in a large population of RT neurons across widespread regions of the slice (Huguenard and Prince, 1994; Sun et al., 2002a).

Because RT cells express high levels of NPY and, thus, are a potential source of synaptically released peptide (Molinari et al., 

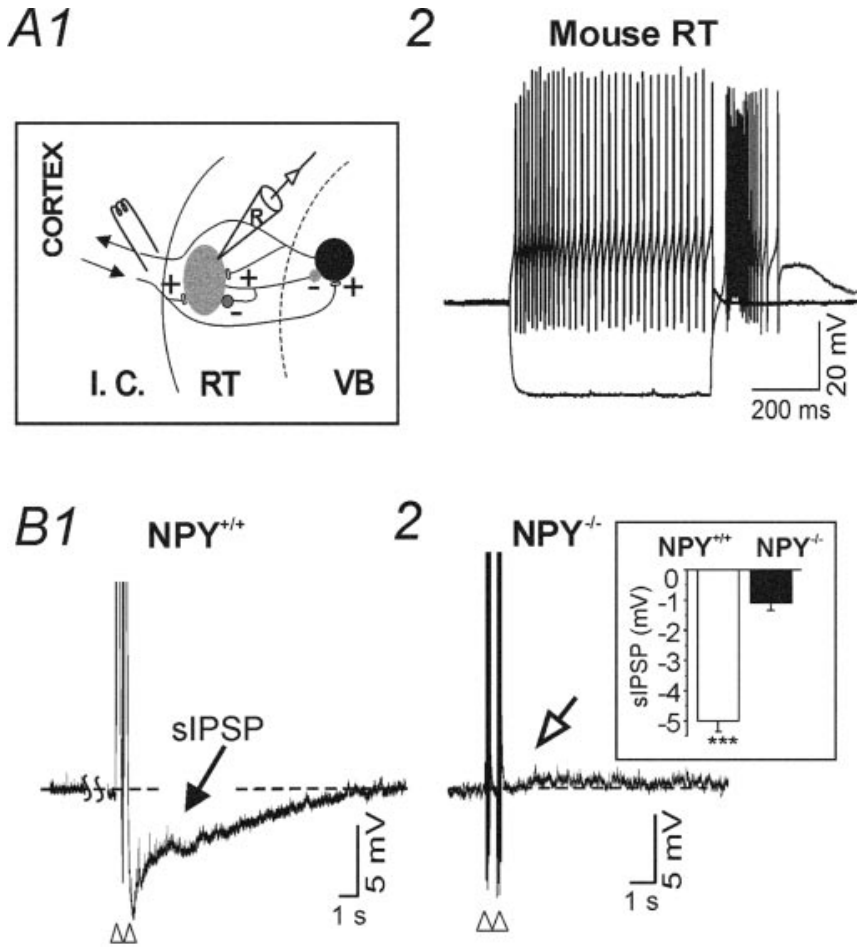

Figure 1. SIPSPs are evoked in RT neurons from wild-type, but not $\mathrm{NPY}^{-/-}$, mice. $A 1$, Schematic depicting the thalamic circuit with recording and stimulation sites. IC, Internal capsule; $\mathrm{RT}$, thalamic reticular nucleus; $\mathrm{VB}$, thalamic ventral basal complex. Patch-clamp recordings (R) were used to monitor membrane responses of RT neurons. +, Corticothalamic and TC excitatory synapses; - , GABAergic inhibitory synapses. A2, Electrophysiological identification of a wild-type mouse RT cell, with characteristic high-frequency firing and rebound burst in response to depolarizing and hyperpolarizing current injections (100 pA), respectively. B, sIPSPs in wild-type and $\mathrm{NPY}^{-1-}$ mice. B1, Trains of synaptic stimuli in NPY ${ }^{+/+}$mice elicited large sIPSPs in RT neurons (black arrow). Each train ( $\triangle$, here and in subsequent figures) was composed of four stimuli (1.5 V, $40 \mu \mathrm{S}, 25 \mathrm{~Hz})$ applied to the internal capsule. Such sIPSPs were much smaller or absent in NPY ${ }^{-1-}$ mice (B2, open arrow). B2, Inset, Mean sIPSP amplitude, measured 1 sec after the last stimulus, in $\mathrm{NPY}^{+/+}$mice $(n=17)$ and $\mathrm{NPY}^{-/-}$mice $(n=16$; $\left.{ }^{* * *} p<0.001\right)$.

1987; Morris, 1989), we determined whether repetitive activation of RT cells in the presence of BMI would lead to identifiable electrophysiological actions caused by release of NPY. Stimulus trains applied to the internal capsule (1-5 V, 40-50 $\mu$ sec; four stimuli at $20-25 \mathrm{~Hz}$; Fig. $1 \mathrm{~A} 1$, experimental diagram) resulted in multiple spike bursts in RT neurons. Total spike counts increased dramatically as a function of the number of stimuli within the train, because of supralinear summation of the evoked compound EPSPs (Steriade, 2001; Sun et al., 2002a). Typically, a group of two or more of such short stimulus trains (Fig. $1 B$, individual trains indicated by $\Delta$ ) were applied at $3.3 \mathrm{~Hz}$ to elicit rhythmic burst discharges in RT neurons. After the stimulus train-induced bursting, long-lasting membrane hyperpolarizations (Fig. $1 \mathrm{B1}$, arrow; $>5 \mathrm{sec}$ duration; mean peak amplitude, $-5.1 \pm 0.7 \mathrm{mV} ; n=17$ ) were routinely observed in RT cells. These did not arise from the intrinsic properties of these cells, because prolonged action potential trains evoked by maintained or repetitive intracellular current injections evoked either undetectable (see Fig. 5A1) or small and brief AHPs (see Fig. 5A2, inset; amplitude, $-1 \pm 0.4 \mathrm{mV}$; duration, $156 \pm 33 \mathrm{msec} ; n=$ 18). The directly evoked AHPs were small under these conditions, probably resulting from both the high amount of EGTA (10 $\mathrm{mM}$; see Materials and Methods) in the patch pipette solution (Sodickson and Bean, 1996; Chen and Regehr, 1999; Rozov et al.,
2001) and the application of BMI-containing perfusate that is known to block the slow AHP in these cells (Debarbieux et al., 1998). Because the stimulus-induced prolonged hyperpolarizations seem to be synaptic in nature, we refer to them here as sIPSPs. Their dependence on stimulus conditions and other physiological properties will be discussed in more detail below.

To determine whether the sIPSPs might result from NPY release, we next tested for their presence in RT neurons of NPYdeficient mice (Erickson et al., 1996). The long-lasting hyperpolarizations were either absent or much smaller in amplitude $\left(-1.1 \pm 0.2 \mathrm{mV} ; n=16 ; p<0.001 \mathrm{vs} \mathrm{NPY}^{+/+}\right.$; Figs. 1 B2, open arrow and inset, $3 B 1$ ). In contrast, other neuronal properties, such as resting membrane potential $(-67 \pm 0.8 \mathrm{mV}, n=18$ in $\mathrm{NPY}^{-/-}$vs $\left.-64 \pm 1.1 \mathrm{mV}, n=30 \mathrm{in} \mathrm{NPY}^{+/+}\right)$, input resistance $\left(226 \pm 10 \mathrm{M} \Omega, n=18\right.$ in $\mathrm{NPY}^{-/-}$vs $205 \pm 11 \mathrm{M} \Omega, n=30$ in $\mathrm{NPY}^{+/+}$), and spike/burst morphologies were not significantly different between NPY ${ }^{-1-}(n=18)$ and NPY ${ }^{+/+}(n=30)$ mice, suggesting that intrinsic neuronal excitability was unaffected by the knock-out NPY.

These data suggest that the RT cell long-lasting hyperpolarization induced by trains of extracellular stimuli is not an AHP resulting from repetitive firing, but rather is an sIPSP resulting from the action of NPY released during the stimulus.

\section{Exogenous activation of $\mathrm{Y}_{1}$ receptors hyperpolarizes mouse RT cells}

We first confirmed that $Y_{1}$ receptors were present in murine RT neurons and that $\mathrm{Y}_{1}$-dependent responses of these neurons were similar to those previously found in rat (Sun et al., 2001a). Recorded mouse RT neurons were filled with biocytin (Fig. 2A1), and the sections subsequently reacted with $Y_{1}$ receptor antibody. As shown in Figure 2, $A 2$ and $A 3, \mathrm{Y}_{1}$ receptor immunoreactivity was present at high levels in RT, with prominent staining on somata and dendrites of reticular neurons, suggesting a predominantly postsynaptic site of action. In both $\mathrm{NPY}^{+/+}$and NPY ${ }^{-1-}$ mouse RT neurons, the $\mathrm{Y}_{1}$ agonist Leu ${ }^{31}$ Pro ${ }^{34} \mathrm{NPY}(100-300$ $\mathrm{nM})$ consistently produced membrane hyperpolarizations $\left(\mathrm{NPY}^{+/+}:-5 \pm 1.5 \mathrm{mV} ; n=11\right.$ of 11 responding; $p<0.001$; Fig. $2 B 1, B 3 ; \mathrm{NPY}^{-/-}:-5.1 \pm 1.8 \mathrm{mV} ; n=6$ of 6 cells responding; $p<0.001$; Fig. 2B2,B3) and inhibition of neuronal discharge (data not shown). The degree of hyperpolarization was not significantly different between NPY ${ }^{+/+}$and NPY ${ }^{-1-}$ RT cells $(p>$ 0.5 ; Fig. 2 B3), suggesting that the genetic deletion of the endogenous neuropeptide induced little compensatory change in $\mathrm{Y}_{1}$ receptor expression or function. Consistent with these electrophysiological data, the density and expression patterns of $Y_{1}$ immunoreactivity in sections from thalamus in three $\mathrm{NPY}^{-1-}$ mice were similar to those seen in NPY ${ }^{+/+}$mice of similar age (data not shown). In other experiments, the $\mathrm{Y}_{1}$ agonist Leu ${ }^{31} \mathrm{Pro}^{34} \mathrm{NPY}$ (100-300 nM) activated an inwardly rectifying current in both $\mathrm{NPY}^{+/+}$and $\mathrm{NPY}^{-/-}$RT neurons (Fig. $2 C ; n=5$ in each group). Therefore, $\mathrm{Y}_{1}$ receptors have similar expression and functional coupling in RT neurons of rats and mice.

\section{sIPSPs result from activation of $\mathrm{Y}_{1}$ receptors coupled to GIRK channels}

We have shown previously that the postsynaptic effects of exogenous NPY application on rat RT neurons are blocked by the $\mathrm{Y}_{1}$ antagonist BIBP3226 (Sun et al., 2001a,b). We next examined the effects of BIBP3226 on sIPSPs to determine whether they would be affected similarly, as expected for an NPY-dependent response. RT neuron sIPSPs were blocked reversibly by $1 \mu \mathrm{M}$ BIBP3226 (control: $-5.1 \pm 0.7 \mathrm{mV} ; n=11$; BIBP3226: $-1 \pm 0.5$ 
$\mathrm{mV} ; n=11 ; p<0.001$; Fig. $3 A, C)$ in $\mathrm{NPY}^{+/+}$mice. In contrast, BIBP3226 had no effect on the very small sIPSPs observed in RT cells of $\mathrm{NPY}^{-/-}$mice (control, $-1.1 \pm 0.4 \mathrm{mV}$ vs BIBP3226, $-0.7 \pm 0.3$ $\mathrm{mV} ; n=12$; not significant; Fig. 3, compare $B 2$ with $B 1, C 1, C 2)$.

Exogenous $\mathrm{Y}_{1}$ receptor activation has been shown to cause GIRK channel opening in rat thalamic neurons (Sun et al., 2001a,b). Therefore, we tested the effects of a GIRK channel blocker on mouse RT neuron sIPSPs and found that these were eliminated by $0.1 \mathrm{mM} \mathrm{Ba}^{2+}(p<0.001$; $n=6$; data not shown). We next examined the temporal changes in membrane conductance associated with the NPYmediated sIPSP in mouse RT neurons. Repetitive hyperpolarizing currents $(-40$ $\mathrm{pA}, 50 \mathrm{msec}, 10 \mathrm{~Hz}$ ) were injected intracellularly to provide an assay of input conductance before and after synaptic train stimuli (Fig. 4A1). There was an apparent increase in membrane conductance beginning after the first stimulus train and reaching peak amplitude $\sim 1$ sec after termination of the stimuli. This was followed by a gradual conductance decline over several seconds (Fig. 4A1,A2). The membrane conductance measured $1 \mathrm{sec}$ after the train was increased above control by $67 \pm 8 \%$ (Fig. 4 B1, left; $n=9 ; p<0.01$; paired $t$ test vs prestimulation) and recovered within $5 \mathrm{sec}$ (Fig. 4B1, left). In $\mathrm{NPY}^{+/+}$mouse RT neurons, the increase in membrane conductance was abolished by perfusion with $1 \mu \mathrm{M}$ BIBP3226 but recovered after BIBP3226 washout (Fig. $4 B 1 ; n=9)$. Figure $4 B$ shows these effects of NPY and BIBP3226 on membrane conductance in the nine RT neurons examined and indicates that $\mathrm{Y}_{1}$ receptors mediate the membrane conductance changes. In NPY-deficient mice, there was no significant membrane conductance increase $1 \mathrm{sec}$ after train termination (Fig. 4B2,B3). Furthermore, BIBP3226 had no effect on the resting membrane resistance in $\mathrm{NPY}^{-1-}$ mice $(241 \pm 13 \mathrm{M} \Omega$ in BIBP3226 vs $227 \pm 10 \mathrm{M} \Omega$ in controls; $p>0.2 ; n=9)$ or on the membrane resistance after the synaptic stimulation (Fig. $4 B 2, B 3 ; 246 \pm 16 \mathrm{M} \Omega ; n=9 ; p>0.2$ vs prestimulation).

To provide additional evidence that the effects of BIBP3226 on the sIPSPs were postsynaptic, $200 \mu \mathrm{M}$ GDP- $\beta$-S (a G-protein hydrolysis inhibitor that blocks G-protein activation) was loaded into $\mathrm{NPY}^{+/+}$mouse RT neurons via the patch pipette solution. In these neurons, sIPSPs were initially detectable $(-4.9 \pm 0.5$ $\mathrm{mV} ; n=4$; Fig. $5 D 1)$ but were nearly abolished after $\sim 30 \mathrm{~min}$ of whole-cell recording $(0.9 \pm 0.5 \mathrm{mV} ; n=4 ; p>0.1$ vs controls; Fig. $4 C 1, C 2)$. In contrast, RT neurons recorded with normal patch pipette solution revealed robust sIPSPs that could be activated repeatedly at $1 \mathrm{~min}$ intervals for at least $1 \mathrm{hr}$ (data not shown). The increased membrane conductance associated with the $\operatorname{sIPSP}$ (Fig. $4 C 1 ; 3 \mathrm{~min} ; n=4 ; p<0.001$ vs prestimulation)
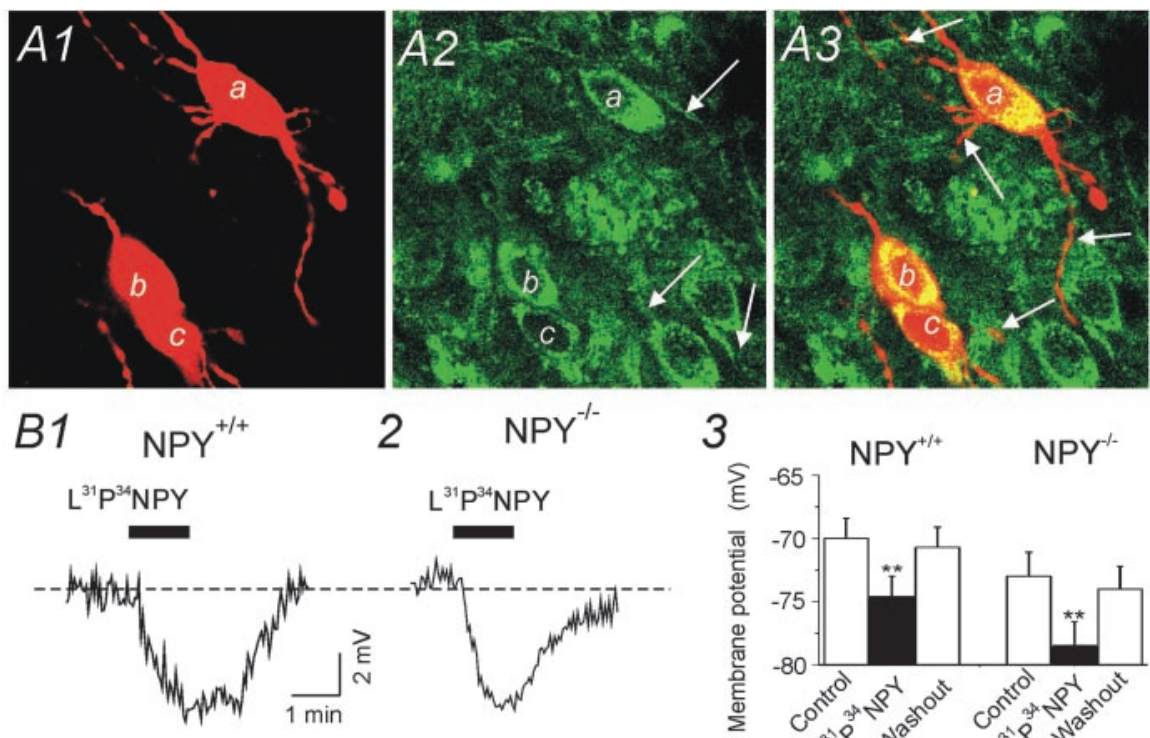

3

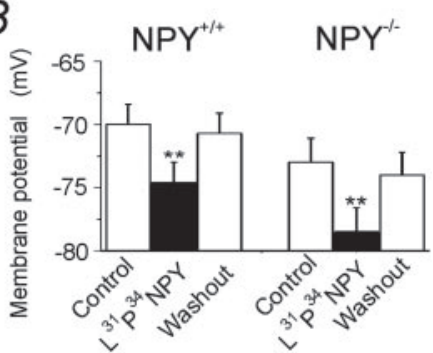

2

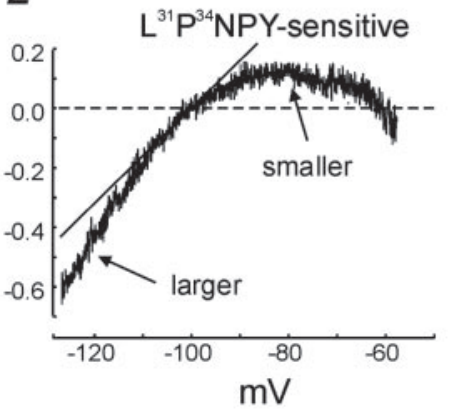

$\mathrm{mV}$

Figure 2. Postsynaptic localization and actions of $Y_{1}$ receptors in mouse $R T$ neurons. $A$, Confocal laser scanning fluorescent co biocytin-labeled neuron with $Y_{1}$ receptor immunoreactivity. B1, B2, Effect of $200 \mathrm{~nm} \mathrm{Leu}{ }^{31}$ Pro ${ }^{34} \mathrm{NPY}$ on resting membrane potentials in RT neurons from NPY ${ }^{+/+}(B 1)$ and $\mathrm{NPY}^{-1-}(B 2)$ mice, respectively. B3, Summary effects of ${ }^{30} \mathrm{NPY}$ on RT cell resting membrane potentials in NPY ${ }^{+/+}(n=11)$ and NPY ${ }^{-1-}$ mice $\left(n=6 ;^{* *} p<0.01\right)$. $C_{\text {, }}$

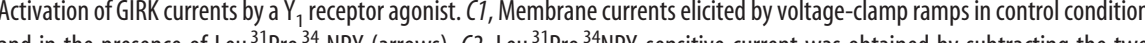
current traces in C1. Dashed lines in $C 1$ and $C_{2}, 0 \mathrm{pA}$; solid line in $\mathrm{C}$, extrapolated line from linear fit for membrane currents at voltages near $( \pm 10 \mathrm{mV})$ the reversal potential $(-100 \mathrm{mV})$. Note that the Leu ${ }^{31} \mathrm{Pro}^{34} \mathrm{NPY}$-sensitive current is greater than the extrapolated value in the inward direction but smaller in the outward direction.

was also blocked after $30 \mathrm{~min}$ (Fig. 4 C3; $30 \mathrm{~min} ; n=4 ; p>0.1$ vs prestimulation). Application of BIBP3226 after 30 min of recording from GDP- $\beta$-S-loaded cells had no effect on either resting membrane potential or input resistance (Fig. $4 C 1-C 3 ; n=4$ ). These results suggest that the BIBP3226-dependent increased membrane conductance associated with the sIPSP is mediated via activation of postsynaptic G-protein-mediated responses.

In summary, stimulation of corticothalamic fibers in vitro strongly activates mouse GABA/NPYergic RT neurons and results in long-lasting $(\sim 10 \mathrm{sec})$ feedforward $\mathrm{Y}_{1}$ receptordependent and GIRK-dependent sIPSPs in the same cells. To directly compare responses mediated by a classical neurotransmitter (GABA) with a neuropeptide (NPY) coreleased from the same presynaptic neurons, we designed experiments to test whether the sIPSP was present in TC relay neurons, the major target of RT cell axons. In these cells, we could then compare the sIPSP with a previously characterized sIPSP mediated by GABA $_{B}$ receptors (Soltesz et al., 1988; Crunelli and Leresche, 1991; von 

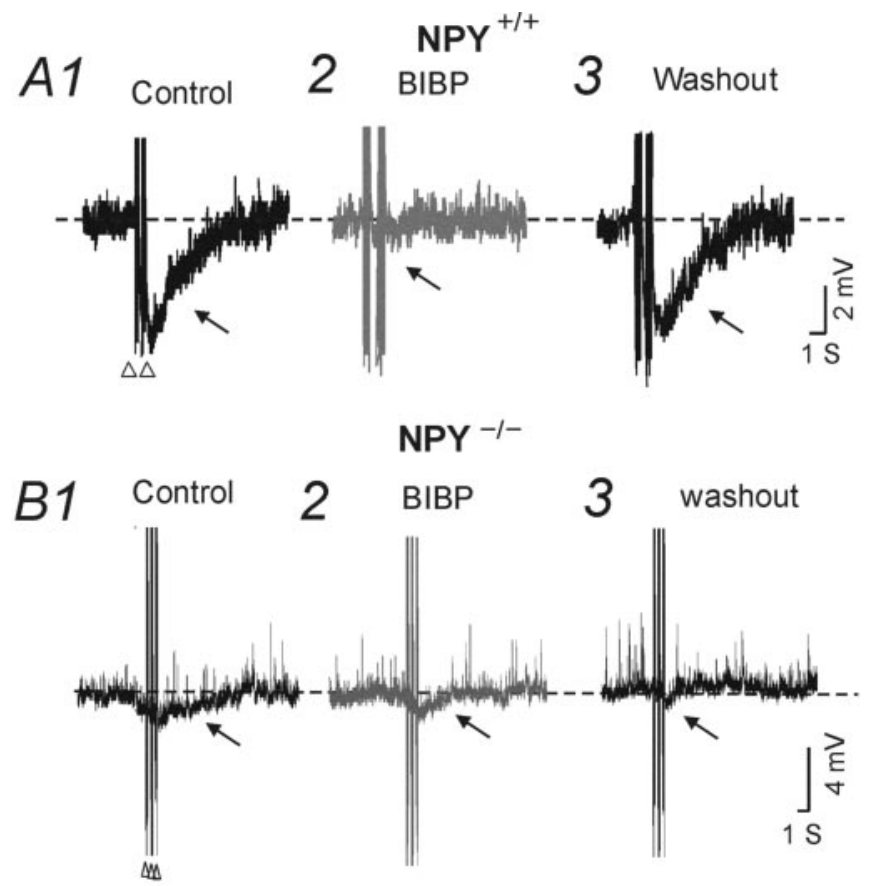

C1

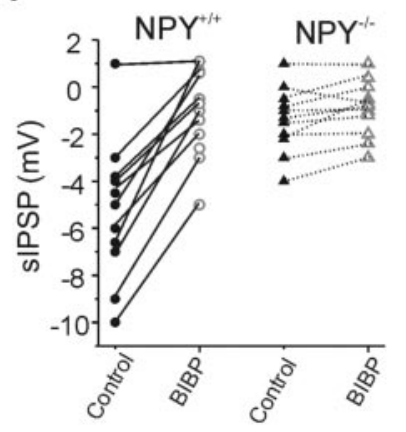

C2

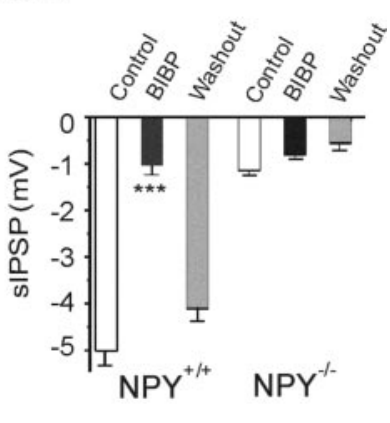

Figure 3. Endogenous NPY, via $\mathrm{Y}_{1}$ receptors, activates sIPSPs in RT neurons of NPY ${ }^{+/+}$, but not NPY ${ }^{-1-}$ mice. A1, Whole-cell recordings of evoked burst discharges (spikes truncated), followed by sIPSPs in an NPY ${ }^{+/+}$RT neuron in control solution (A1), in solution containing 1 $\mu \mathrm{M}$ BIBP3226 (A2, gray traces), and after drug washout (A3). Arrows in $A 1$ and $A 2$ indicate SIPSPs. Triangles each represent a stimulus train applied to the internal capsule. The stimulus train parameters are as in Figure $1 B 1(1.5 \mathrm{~V}, 40 \mu \mathrm{S}, 25 \mathrm{~Hz})$. B, Recordings of burst discharges (spikes truncated) and membrane responses elicited by three trains of synaptic stimulation in an RT neuron (NPY ${ }^{-/-}$) in control solution (B1), in the presence of BIBP3226 (B2), and after drug washout (B3). Arrows in $B 1$ and $B 2$ point to hyperpolarizations after stimulus trains that are smaller, briefer, and unaffected by BIBP3226 compared with those RT neurons from $\mathrm{NPY}{ }^{+/+}$mice (compare $A 1$ and $A 2$ with $B 1$ and $B 2$ ). (1, Mean sIPSC amplitudes in individual $\mathrm{NPY}^{+/+}$and NPY ${ }^{-/-}$RT neurons under control conditions (filled symbols) and after exposure to $1 \mu \mathrm{M}$ BIBP3226 (open symbols). Each line represents a different RT cell. Solid lines, NPY +/+ mice; dashed lines, NPY ${ }^{-1-}$ mice. $(2$, Mean sIPSC amplitude in RT neurons in control (open bar), during BIBP3226 application (filled black bar), and after washout (filled gray bar) in RT neurons from NPY ${ }^{+/+}(n=11)$ and NPY ${ }^{-I-}(n=11)$ mice. ${ }^{* * *} p<0.0001$, BIBP3226 versus control and washout.

Krosigk et al., 1993; Kim et al., 1997; Ulrich and Huguenard, 1999). Because such experiments would require $\mathrm{GABA}_{\mathrm{A}}$ receptor blockade with bicuculline to obtain robust synaptic activation of RT cells (see below) and $\mathrm{GABA}_{\mathrm{B}}$-dependent IPSPs are small and functionally weak in mouse relay neurons (Warren et al., 1994, 1997; Warren and Jones, 1997), these experiments could not be performed in mice. Instead, we made this comparison in rat thalamic slices, which have a number of advantages, including: (1) thalamic relay neurons express well characterized RT cell- dependent $\mathrm{GABA}_{\mathrm{B}}$-dependent IPSPs (Huguenard and Prince, 1994; Ulrich and Huguenard, 1999); (2) rat thalamic slices are amenable to in vitro studies of oscillatory network interactions and their modulation by peptides and other agents (Huguenard and Prince, 1994; Cox et al., 1997; Sun et al. 2002a;), and (3) we have demonstrated previously in rat thalamic RT and ventrobasal (VB) neurons that exogenous NPY application results in activation of both $Y_{1}$ and $Y_{2}$ receptors, which are coupled to postsynaptic GIRK channels and presynaptic $\mathrm{Ca}^{2+}$ channels, respectively (Sun et al., 2000a,b).

Target-specific postsynaptic NPYergic synaptic inhibition in rat thalamic slices

We performed simultaneous whole-cell patch-clamp recordings from visualized rat RT and TC neurons to measure postsynaptic responses evoked by the same stimulus delivered to the corticothalamic tract (Fig. 1A1). TC recordings were obtained from neurons in the somatosensory VB complex. As in the mouse, we determined whether repetitive activation of RT cells under conditions of $\mathrm{GABA}_{\mathrm{A}}$ receptor blockade would lead to identifiable electrophysiological actions because of the release of NPY.

As shown in Figure 5, $A 2$ and B2, a single shock to the internal capsule elicited a spike burst (Fig. 5A2, gray trace) in an RT neuron, followed by a very small but long-lasting ( $\sim 2 \mathrm{sec}$ ) sIPSP (Fig. $5 A 2$, large arrow). Increasing the numbers of stimuli within the train evoked progressively longer depolarizations, increased numbers of spikes (Fig. 5A2), and larger sIPSPs (Fig. 5A2, large arrow). Repeated stimulus trains (at $3 \mathrm{~Hz}$ ) elicited repetitive burst discharges and sIPSPs of progressively larger amplitude and duration (Fig. 6A, large arrows). Amplitude and duration of the sIPSPs were linear functions of train number (Figs. $5 A, 6 A, A 2$, inset; $n=26$ cells). As in the mouse, prolonged action potential trains evoked by either maintained or repetitive intracellular current injections ( $1 \mathrm{~Hz}, 200 \mathrm{msec}, 300 \mathrm{pA}$; Fig. 5A2, inset) evoked either undetectable (Fig. 5A1) or small and brief (Fig. 5A2, inset) AHPs in these neurons (amplitude, $1 \pm 0.4 \mathrm{mV}$; duration, $156 \pm$ 33 msec; $n=18$ ).

In contrast to the sIPSPs observed in RT cells, simultaneous intracellular recordings from VB neurons revealed that the same stimulation protocol elicited repetitive medium-duration IPSPs $(\sim 200-300 \mathrm{msec})$ in relay neurons (Figs. 5B2, 6B, open arrows vs Figs. 5A2, 6A, large black arrows denoting sIPSPs). The onset of the bursts in RT neurons immediately preceded the IPSPs in VB relay cells, suggesting that the latter were mediated by neurotransmitter released from RT neurons (Fig. 5, B2 vs A2, dotted vertical line denoting onset of RT burst). Previous studies have shown that such medium-duration IPSPs in relay neurons are mediated by $\mathrm{GABA}_{\mathrm{B}}$ receptors activated by the release of endogenous GABA from GABAergic neurons (Soltesz et al., 1988; Crunelli and Leresche, 1991; Kim et al., 1997). In contrast to the RT cell sIPSCs, which required several stimulus trains for their robust expression, large $\mathrm{GABA}_{\mathrm{B}}$ IPSPs occurred after single burst discharges of RT neurons (Fig. 5B2, gray trace). Increasing the number of stimuli within the train evoked progressively larger $\mathrm{GABA}_{\mathrm{B}}$ IPSPs in relay neurons (Fig. $5 \mathrm{~B} 2$, open arrow). In contrast to the RT neuron sIPSPs, the GABA $_{B}$ IPSPs in relay neurons did not summate, but rather showed significant attenuation when evoked repetitively (Fig. 6, B2 vs $A 2$, compare insets). Further-

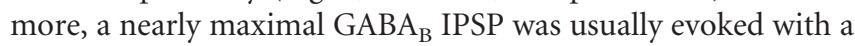
single train of only four extracellular stimuli (1-5 V, 40-50 $\mu \mathrm{sec}$, $25 \mathrm{~Hz}$; Fig. 5B2). Even a larger number of stimuli (6-10 trains; $n=6$ cells; data not shown) failed to evoke a significant sIPSP. 
These results show that repetitive firing of RT neurons evoked differential postsynaptic effects in RT and VB cells.

As with mice, we found that the selective $\mathrm{NPY}_{1}$ receptor antagonist BIBP3226 blocked the rat RT neuron sIPSPs (Fig. 7A; $n=27 ; p<0.001) . \mathrm{Y}_{1}$-sensitive responses, obtained by subtracting membrane responses recorded in BIBP3226 from those in control conditions, showed the characteristics of the sIPSP (Fig. 7A1, inset). BIBP3226sensitive IPSPs were characterized by monoexponential decay with a mean time constant of $2.7 \pm 0.3 \mathrm{sec}$ (Fig. 7A1; $n=12$ ). Other properties of the rat RT sIPSPs, such as reversal potential $(-95 \pm 4 \mathrm{mV} ; n=7$; data not shown), sensitivity to $\mathrm{Ba}^{2+}$ block ( $0.1 \mathrm{mM} ; n=4$; data not shown), and occlusion by $\mathrm{Y}_{1}$ agonist Leu ${ }^{31}$ Pro ${ }^{34} \mathrm{NPY}(200 \mathrm{nM}$; $n=6$; data not shown) were similar to those described for mouse RT neurons. The $\mathrm{GABA}_{\mathrm{B}}$ receptor antagonist CGP55485 (10 $\mu \mathrm{M})$ had no significant effect on sIPSPs in four of four RT neurons $(-5.3 \pm 1.1 \mathrm{mV}$ in controlvs $-5.0 \pm 0.8 \mathrm{mV}$ in CGP55845; $p>$ 0.5 ; Fig. $7 A 3$, inset), suggesting minimal contribution of $\mathrm{GABA}_{\mathrm{B}}$ receptors to the sIPSP.

We found little or no evidence for sIPSPs in rat VB neurons (Figs. 5B2, 6B, 7B), despite the fact that exogenous application of NPY and $Y_{1}$ agonists effectively hyperpolarizes these neurons via the same mechanisms as in RT cells (Sun et al., 2001a). Instead, medium-duration IPSPs were the predominant response, with reversal potentials and time course expected for $\mathrm{GABA}_{\mathrm{B}}$ receptor-mediated events (Crunelli and Leresche, 1991; von Krosigk et al., 1993; Kim et al., 1997). The latter were blocked by the selective $\mathrm{GABA}_{\mathrm{B}}$ receptor antagonist CGP55845 (10 $\mu \mathrm{M}: n=15,-0.6 \pm 1$ $\mathrm{mV}, p<0.01$ vs controls: $-12 \pm 1 \mathrm{mV}$, $n=15$; Fig. 7B2,B3), often revealing corticothalamic EPSPs. In contrast to the complete suppression of the sIPSP by the $\mathrm{Y}_{1}$ antagonist BIBP3226 in RT neurons, this compound had little or no effect on the $\mathrm{GABA}_{\mathrm{B}}$ IPSPs in relay neurons $(-10 \pm 0.6 \mathrm{mV}$ in BIBP vs $-11.2 \pm 1 \mathrm{mV}$ in controls; $n=23 ; p<0.01$; Fig. 7B1,B3). Although no clear sIPSPs were seen in VB neurons, the net late (1000 msec after termination of the stimulus trains) hyperpolarization evoked by stimulus trains was not completely blocked by CGP55845 (Fig. $7 B 3)$, and BIBP perfusion produced a small but significant decrease in the response (Fig. 7B3), suggesting a minor $(<10 \%)$ NPYergic contribution to postsynaptic responses in relay cells.

\section{Endogenous release of NPY modulates thalamic} paroxysmal oscillations

In rat thalamic slices bathed with $10 \mu \mathrm{M}$ BMI to block $\mathrm{GABA}_{\mathrm{A}}$ receptor-mediated IPSPs, highly synchronized network oscillaversus control.
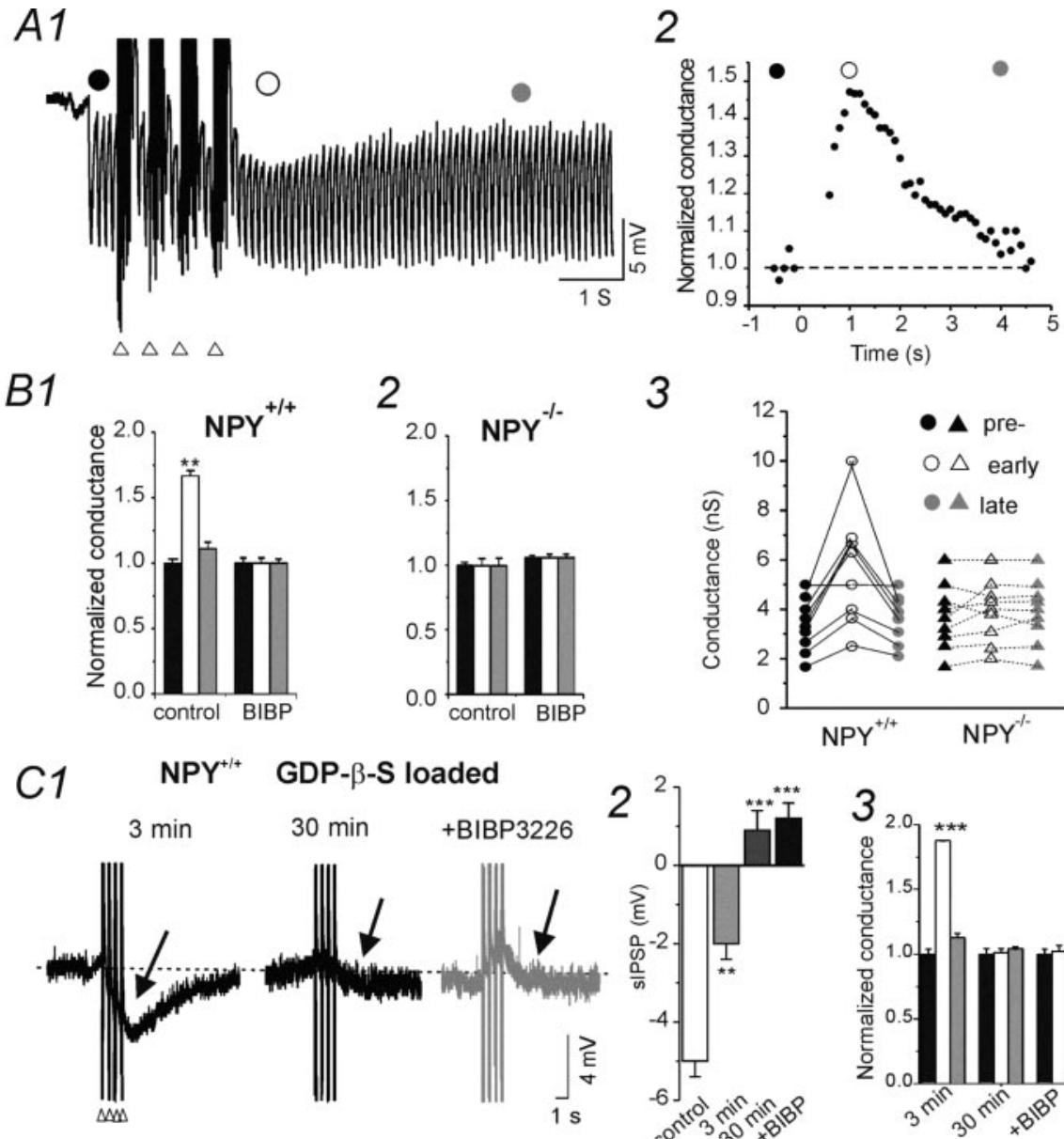

Figure 4. SIPSCS result from G-protein and $\mathrm{Y}_{1}$-dependent increases in membrane conductance. $A 1$, Whole-cell current-clamp recordings of an $\mathrm{NPY}^{+/+}$mouse $\mathrm{RT}$ neuron (action potentials truncated) in which intracellular current injections $(10 \mathrm{~Hz}, 20 \mathrm{pA}, 50$ msec) were used to assess input conductance before, during, and after sIPSC-inducing stimuli. Input conductance is increased immediately after stimulus trains (open circle) compared with that obtained before the stimulus (black circle) and returns to control within $\sim 5 \mathrm{sec}$ (gray circle). A2, Normalized membrane conductance as a function of time in the same neuron. Large circles indicate times of measurement as shown in $A 1 . B 1, B 2$, Mean normalized membrane conductance measured 0.1 sec before (black bar), 1 sec after (open bar), and 4 sec after (gray bar) synaptic stimulation of RT neurons from NPY $+1+(B 1 ; n=9)$ and NPY ${ }^{-/-}$ mice $(B 2 ; n=9)$ recorded in control condition (left bars) and after perfusion with solution containing $1 \mu \mathrm{M}$ BIBP3226 (right bars). ${ }^{* *} p<0.001$ for conductance change at peak of sIPSP versus control in NPY ${ }^{+/+}$mice. B3, Membrane conductance of individual RT neurons before stimuli (filled circles or triangles), 1 sec after stimuli (open circles or triangles), and 4 sec after stimuli (gray circles or triangles). Solid lines and circles (left), NPY ${ }^{+1+}$ mice; dashed lines and triangles (right), NPY ${ }^{-1-}$ mice. $(1$, Whole-cell current-clamp recordings from an NPY ${ }^{+/+}$mouse RT neuron loaded with $200 \mu \mathrm{M}$ GDP- $\beta$-S. Burst discharges and sIPSPs (arrow) were elicited by train stimuli (open triangles) applied to internal capsule. Representative recordings are shown at 3 min (left trace) and $30 \mathrm{~min}$ (middle trace) after initial whole-cell membrane rupture in control solution (left and middle) and during subsequent application of BIBP3226 (1 $\mu \mathrm{m}$, right). Arrows in the $30 \mathrm{~min}$ and BIBP3226 traces are positioned at the same point as the arrow in the 3 min trace and show absence of SIPSP. C2, Mean sIPSP amplitude in four NPY ${ }^{+/+}$mouse GDP- $\beta$-S-loaded RT neurons shortly after membrane rupture (open bar), at $3 \mathrm{~min}$ after (light gray bar) and $30 \mathrm{~min}$ after (gray bar) establishment of whole-cell configuration, and during later application of BIBP3226 (1 $\mu \mathrm{m}$; black bar). ${ }^{* *} p<0.01$ for sIPSP amplitude versus control; ${ }^{* * *} p<$ 0.001 for peak sIPSP conductance versus control. (3, Normalized membrane conductance measured 0.1 sec before (black bar), 1 sec after (open bar), and 4 sec after (gray bar) synaptic stimuli in the four neurons of $C 2$. ${ }^{* *} p<0.001$ for peak sIPSP conductance

tions $(\sim 3 \mathrm{~Hz})$, resembling the thalamic activity observed during spike-wave seizures (von Krosigk et al., 1993; Huguenard and Prince, 1994; Huguenard, 1999), were elicited by extracellular stimulation of the internal capsule. The synchronized network activities were relatively stable over a period of $\geq 1 \mathrm{hr}$ under our recording conditions (Cox et al., 1997; Sun et al., 2002a). After recording for a control period of $\sim 10 \mathrm{~min}$, NPY (100 nM) was applied via bath perfusion, resulting in shortened duration of evoked oscillatory responses (Fig. 8A1,A2,C,D2; Table 1). The number of bursts per oscillation was also reduced (Fig. $8 A 1, A 2, C$; 


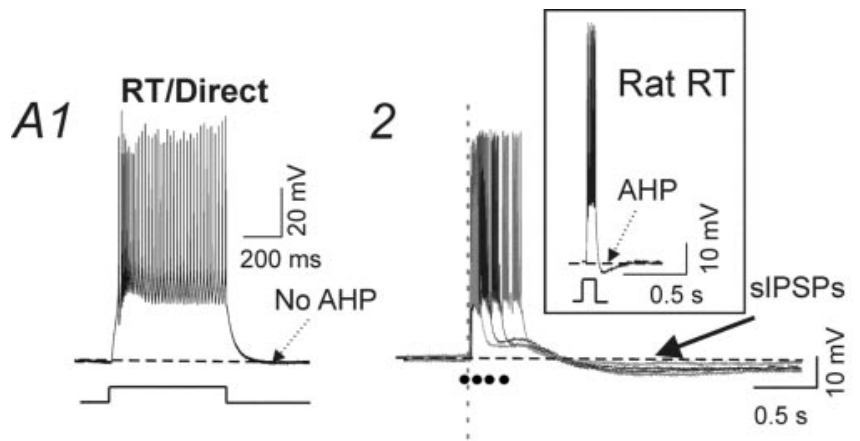

B1
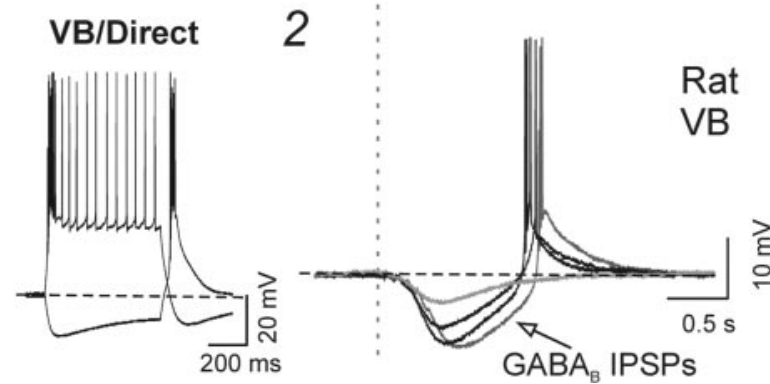

Figure 5. Differential postsynaptic responses evoked in rat $R T$ and VB neurons. $A$, Responses of a rat RT neuron to directly and synaptically evoked depolarization. $A 1$, Intracellular current injection elicited repetitive firing with a characteristic initial burst. Little or no AHP was observed on termination of spiking (small arrow). Dashed lines in all traces of $A$ : resting $V_{\mathrm{m}}=-65 \mathrm{mV}$. $A 2$, Superimposed responses to four different extracellular stimulus trains containing one, two, three, and four stimuli applied at $25 \mathrm{~Hz}$ (each filled circle represents a single $1.5 \mathrm{~V}, 40 \mu \mathrm{S}$ stimulus). Evoked spikes and late hyperpolarizations (large arrow) were increased as a function of the number of stimuli within the stimulus train. Inset, Depolarizing current (100 pA, 200 msec) evoked a burst of action potentials, followed by a small amplitude and short-duration AHP (dotted line arrow) in the same neuron. Calibration: $0.5 \mathrm{sec}, 10 \mathrm{mV}$. B1, Intracellular depolarizing and hyperpolarizing current injection elicit typical direct bursts, followed by repetitive firing and a rebound burst, respectively, in a simultaneously recorded VB neuron. Dashed line in all traces of $B$, resting $V_{\mathrm{m}}=-65 \mathrm{mV}$. $B 2$, Superimposed responses to four different extracellular trains containing one, two, three, and four individual stimuli. Increasing numbers of stimuli within each train evoke progressively larger medium-duration IPSPs (open arrow). The vertical dotted line marks the starting onset of the RT cell burst.

Table 1), as were the total number of spikes per episode (Fig. 8C; Table 1) and synchrony as measured by OI (Cox et al., 1997; Huntsman et al., 1999; Sun et al., 2002a). The dominant frequency of the oscillation, measured by fast Fourier transform, dropped from $3.2 \pm 0.5 \mathrm{~Hz}$ in control conditions to $2.5 \pm 0.4 \mathrm{~Hz}$ after NPY application (Fig. 8A1,A2; Table 1). These effects were mimicked by the $\mathrm{NPY}_{1}$ receptor agonist Leu ${ }^{31}$ Pro ${ }^{34} \mathrm{NPY}(100$ nM; $n=4$; data not shown). The decrease in bursts/oscillation elicited by Leu ${ }^{31}$ Pro ${ }^{34} \mathrm{NPY}(32 \pm 4 \%$; $p<0.05 ; n=4$; data not shown) was similar to that after NPY application (Fig. 8D2). These results suggest that exogenous activation of NPY receptors, specifically NPY 1 receptors, caused significant depression of epileptiform network activities.

The addition of BIBP3226 (30 nM) produced opposite effects on oscillations, including an increase in oscillation duration (Fig. $8 B 1, B 2, C, D 1$; Table 2), an increase in the number of bursts (Fig. $8 B 1, B 2, C, D 1$; Table 2), and an increase in total spikes per episode (Fig. 8B1,B2; Table 2). In 7 of 11 experiments, BIBP3226 increased the OI (Fig. $8 C$; Table 2), the number of spikes per episode, and the duration of oscillation (Fig. 8 B1,B2). In the remaining four experiments, BIBP3226 enhanced background activities, so that it was not possible to quantify synchronous oscillatory activity (data not shown). Nevertheless, the total number of spikes per response in these four experiments also increased (Ta-

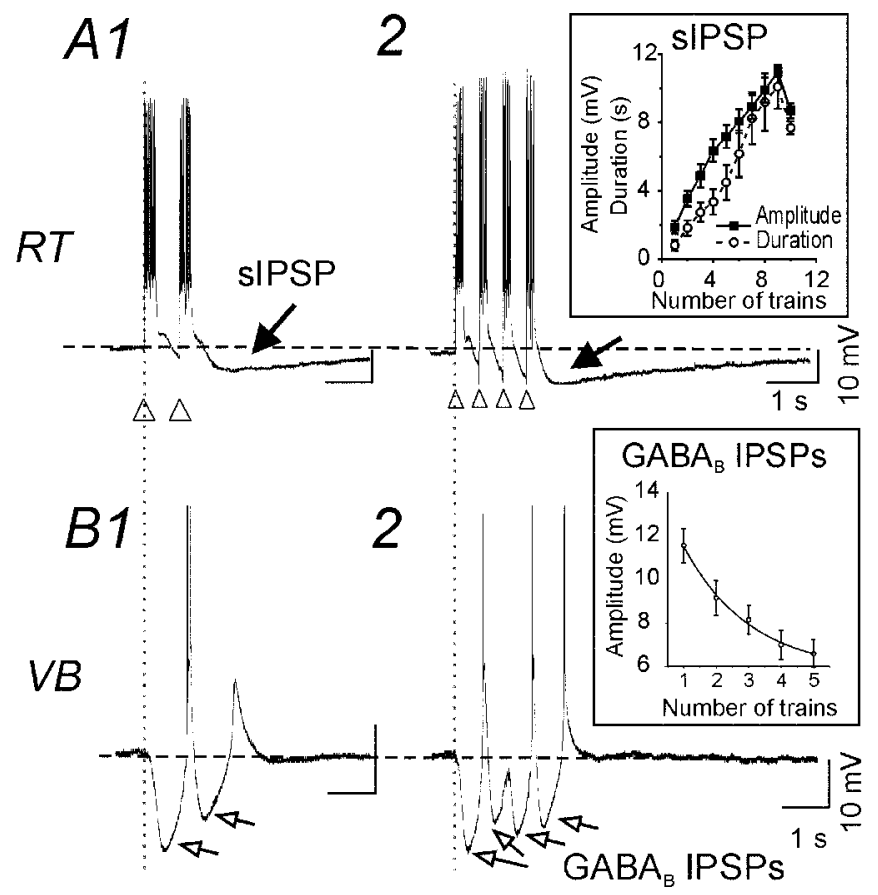

Figure 6. Slow- and medium-duration IPSPs are evoked by internal capsule stimulation in rat $\mathrm{RT}$ and VB neurons, respectively. $A 1, A 2$, Recordings obtained from the same RT neuron in Figure 5A2. sIPSPs of increasing amplitude and duration (large arrows) result from increasing numbers of stimulus trains delivered at $3 \mathrm{~Hz}$. $A 1$, Inset, Mean sIPSP amplitude and duration as a function of the number of stimulus trains ( $n=26$ RT cells). B1, B2, Recordings obtained from the same VB neuron in Figure 5B2. Repetitive stimulus trains evoke multiple medium-duration IPSPs (open arrows), each corresponding to the time of a spike burst in the RT neuron of $A 1$ and $A 2$. The vertical dotted line marks the starting point of $R T$ burst and onset of medium-duration $G_{B B A}$-mediated IPSPs. $B 2$, Inset, shows mean medium-duration IPSP amplitude evoked by each of five consecutive stimulus trains in 15 VB cells. The solid line is the best fit exponential decay function.

ble 2). In general, BIBP3226 also shortened the interburst interval (Fig. 8, B2 vs A2, arrows; $n=5$ ), an effect opposite to that of NPY. In summary, activation and blockade of $Y_{1}$ receptors produced opposite effects on the thalamic epileptiform oscillations. These findings support the conclusion that NPY is endogenously released during synchronous network oscillations and provides a negative feedback for activity in the thalamic network.

\section{Discussion}

We report three major findings with respect to the action of endogenous NPY on thalamic networks. First, NPY, most likely released from RT cells in which it is highly and uniformly expressed (see below), produces an SIPSP in the same cells. Second, the major output target of RT cells, TC relay neurons, does not generate significant NPYergic sIPSPs, even though $\mathrm{Y}_{1}$ receptors are present in these cells. Instead, in relay neurons, $G_{A B A}$ receptor-dependent medium-duration IPSPs are the predominant response to RT activation, suggesting segregation of neurotransmitter output of the RT cells. Third, antagonism of $\mathrm{Y}_{1}$ receptors results in enhanced thalamic oscillations. Because RT cells are apparently the major target of released NPY, the site of action of the antagonistic network effect is most likely on RT cells. Given that RT neurons are essentially the sole cellular source of NPY in the rodent thalamus (Morris, 1989), and that no NPY immunoreactive fiber staining is observed in the internal capsule in which extracellular NPY-IPSP-evoking stimuli were delivered 


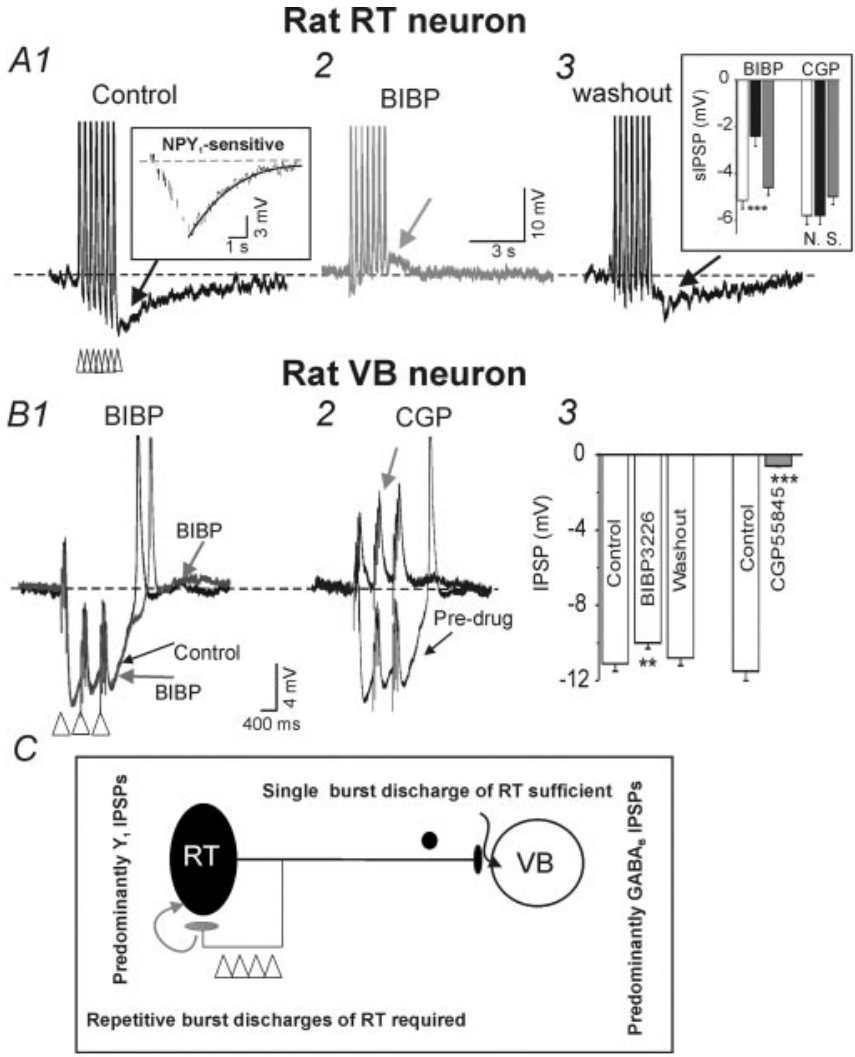

Figure 7. Pharmacology of sIPSPs in RT neurons and medium-duration IPSPs in VB cells. $A$, An sIPSP elicited by seven stimulus trains ( $A 1$, arrow) in a rat RT neuron was abolished by $1 \mu \mathrm{m}$ BIBP3226 (A2) and partially recovered after washout ( $A 3$, arrow). The $Y_{1}$-sensitive membrane potential change ( $A 1$, inset) was obtained by subtracting the averaged responses elicited during BIBP3226 application from those elicited in control conditions. The fitted curves represent exponential decay with a time constant of $1.8 \mathrm{~S}$. A3, Inset, Mean peak amplitude of RT cell-evoked sIPSPs in control (open bar), during BIBP3226 or (GP55845 perfusion (black bars), and after drug washout (filled gray bars). BIBP significantly reduced the SIPSP $\left(n=27 ;{ }^{* * *} p<0.001\right)$, whereas (GP55845 had no effect ( $n=4 ; p>0.5$ vs controls). N.S., Not significant. B1, B2, Trains of extracellular stimuli ( $3 \mathrm{~Hz}$ intertrain frequency) elicited compound PSPs in VB neurons consisting of summated EPSPs and GABA ${ }_{B}$ IPSPs (dark traces). $B 1$, Compound PSPs under control conditions (black trace) and during local perfusion of BIBP3226 (1 $\mu \mathrm{m}$; gray traces). B2, Medium-duration IPSPs were blocked by CGP55845 (10 $\mu \mathrm{m}$; gray traces), revealing composite EPSPs (gray arrow). B3, Mean amplitude of medium-duration IPSPs in control condition and after application of BIBP3226 (left, middle bar) or CGP55845 (right, right bar). ${ }^{* *} p<0.01$ ( $n=$ 23); ${ }^{* * *} p<0.001(n=15)$. C, A schematic depicting segregation of synaptic output from RT cells, with NPY-mediated sIPSPs and GABA ${ }_{B}$-mediated IPSPS, in recurrent versus feedforward synapses, respectively.

(data not shown), these data suggest that the main source of endogenously released NPY is the RT neurons themselves.

The novel actions of endogenous NPY reported here differ from the mainly presynaptic actions of peptides described previously in the hippocampus (Wagner et al., 1993; Weisskopf et al., 1993; Baraban et al., 1997), cerebellum (Miyata et al., 1999), and hypothalamus (Kombian et al., 1997). In the thalamus, NPY causes a direct membrane potential change in postsynaptic neurons via activation of $Y_{1}$ receptors and GIRK channels (Sun et al., 2001a). Although the activation of GIRK channels has been demonstrated to underlie nonpeptidergic classical metabotropic receptor-mediated IPSPs in a variety of CNS neurons (Soltesz et al., 1988; Crunelli and Leresche, 1991; Luhmann and Prince, 1991; Solis and Nicoll, 1992; Dutar et al., 2000), to our knowledge, these results are, thus, the first demonstration of IPSPs produced via an endogenously released neuropeptide in mammalian CNS.
A1

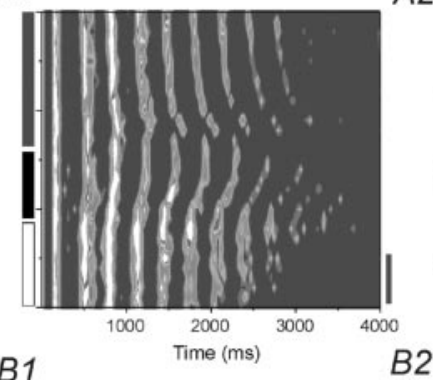

B1

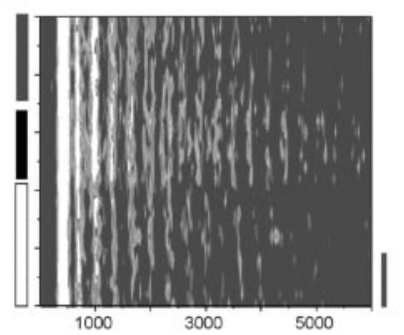

C

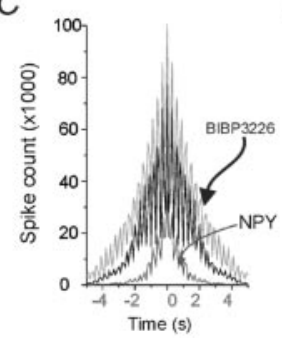

A2

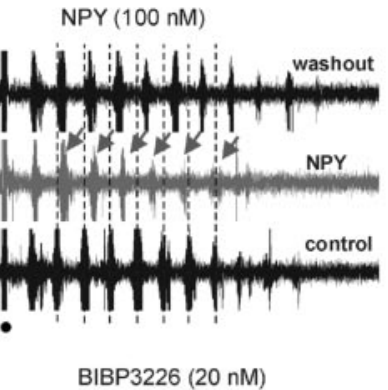

Figure 8. Exogenous and endogenous NPY receptor activation suppresses thalamic network oscillations. $A$, Contour plot (A1) and representative multiunit recordings (A2) showing effects of NPY perfusion on intrathalamic rhythmic oscillations in RT of a rat thalamic slice exposed to bicuculline $(10 \mu \mathrm{m}) . A 1$, Contour plot representing ratemeter of extracellular spikes. The left vertical bar shows time of perfusion with control solution (open bar), NPY (black bar), and after washout (gray bar). The $x$-axis represents time within each evoked oscillation. The $y$-axis represents the time course throughout the experiment (i.e., Pre-drug, NPY, Wash). The z-axis represents the spike intensity during a single evoked oscillation; warmer color levels correspond to a higher frequency of firing. A2, Each trace shows oscillatory burst responses to a single extracellular stimulus in control solution (bottom, black trace), during a $200 \mathrm{~nm} \mathrm{NPY} \mathrm{application}$ (middle, gray), and 10 min after drug washout (top, black). The vertical dashed lines indicate timing of late recurrent bursts in control conditions. The gray arrows point to bursts in NPY that are delayed and reduced in number per response compared with controls. B1, B2, Contour plot (B1) and extracellular multiunit recordings of oscillatory activity (B2) in control solution (bottom), during $20 \mathrm{~nm} \mathrm{BIBP3226}$ application (middle), and after washout (top) in another rat thalamic slice. The vertical dashed lines indicate the time at which bursts occurred in control conditions (bottom). BIBP3226 speeds the oscillation and increases the number of multiunit bursts in the oscillatory response (gray arrows in middle trace). C, Autocorrelograms of the experiments of $A 1$ and $B 1$ showing decreased overall activity (amplitude of central peak) and synchrony (decreased peak to valley ratio) during application of NPY (thin arrow) and increased activity and synchrony during application of BIBP3226 (thick line arrow). Black curve, Control.D, Summary of the effects of NPY (gray bars; $n=7$ ) and BIBP3226 (black bars; $n=11$ ) on network oscillations. D1, The number of spikes per episode (spike count), normalized against controls. D2, Time constant $(\tau)$ of the decay of the oscillation (Huntsman et al., 1999) normalized against controls. ${ }^{*} p<0.05 ;{ }^{* *} p<0.01$ for drug condition versus control.

\section{Target-specific actions of endogenously released NPY}

Recently, a number of laboratories have shown that synaptic transmission from a single presynaptic neuron can have divergent, target-specific features (Reyes et al., 1998; Toth and McBain, 2000; Thomson, 2000; Rozov et al., 2001). Our results, obtained using simultaneous intracellular recordings from excitatory neurons (VB) and inhibitory neurons (RT) in the thalamus, demonstrate that this target specificity can also occur for 
Table 1. Effects of NPY on bicuculline-induced evoked thalamic oscillations in vitro

\begin{tabular}{lcccc}
\hline Parameters & $\begin{array}{l}\text { Control } \\
(n=7)\end{array}$ & $\begin{array}{l}\text { NPY } \\
(n=7)\end{array}$ & $\begin{array}{l}\text { Washout } \\
(n=7)\end{array}$ & $p$ \\
\hline OI (\%) & $81 \pm 3$ & $62 \pm 5^{*}$ & $70 \pm 4$ & $<0.05$ \\
$\tau$ of oscillation (sec) & $2.26 \pm 0.32$ & $1.30 \pm 0.22^{*}$ & $1.79 \pm 0.32$ & $<0.05$ \\
Interburst period (msec) & $310 \pm 5$ & $351 \pm 12^{*}$ & $316 \pm 7$ & $<0.05$ \\
Total spikes (per sweep) & $350 \pm 120$ & $100 \pm 20$ & $290 \pm 50$ & $<0.1$ \\
Number of bursts & $18 \pm 3$ & $11 \pm 1^{* * *}$ & $16 \pm 2$ & $<0.001$ \\
\hline
\end{tabular}

No. of bursts, Number of bursts in each evoked oscillatory episode; Interburst period, interval between consecutive bursts; Total spikes, spikes per episode, averaged across 20 episodes. The time constant $(\tau)$ of decay for oscillations is obtained from the autocorrelogram and is a measure of oscillation duration. This measure, and 01 , which reflects the overall contribution of oscillatory power to the autocorrelation function, are defined in Materials and Methods and in previous publications (Cox et al., 1997; Huntsman et al., 1999; Sun et al., 2002a). ${ }^{*} p<0.05$; ${ }^{* * *} p<0.001$.

Table 2. Effects of BIBP3226 on bicuculline-induced evoked thalamic oscillations in vitro

\begin{tabular}{lcccc}
\hline Parameters & $\begin{array}{l}\text { Control } \\
(n=11)\end{array}$ & $\begin{array}{l}\text { BIBP3226 } \\
(n=11)\end{array}$ & $\begin{array}{l}\text { Washout } \\
(n=11)\end{array}$ & $p$ \\
\hline Ol (\%) & $68 \pm 6$ & $59 \pm 6$ & $58 \pm 6$ & $>0.1$ \\
$\tau$ of oscillation (sec) & $1.37 \pm 0.24$ & $2.12 \pm 0.14^{* *}$ & $1.46 \pm 0.32$ & $<0.01$ \\
Interburst period (msec) & $330 \pm 17$ & $308 \pm 10$ & $353 \pm 35$ & $<0.1$ \\
Total spikes (per sweep) & $160 \pm 50$ & $270 \pm 60^{* *}$ & $190 \pm 50$ & $<0.01$ \\
Number of bursts & $14 \pm 2$ & $19 \pm 1^{* * *}$ & $16 \pm 1$ & $<0.001$ \\
\hline
\end{tabular}

${ }^{* *} p<0.01 ;{ }^{* *} p<0.001$.

peptidergic neurotransmission (Figs. 1, 4). We show that activation of RT neurons generates prominent self-inhibitory NPYergic sIPSPs via their recurrent connections within the nucleus, but not on their extrinsic target neurons in $\mathrm{VB}$, the TC relay cells. This indicates that the inhibitory effects of endogenously released NPY on intrathalamic oscillations occur largely through actions in RT. In contrast, the predominant effect of strong RT activation on relay cells is generation of $\mathrm{GABA}_{\mathrm{B}}$ receptor-mediated IPSPs that are not detected in RT cells. Such differential effects of classical neurotransmitters and neuropeptides released from the same neurons onto two targets represent a novel form of synaptic transmission in the mammalian nervous system.

This segregation of GABA/NPY output of RT cells is consistent with the concept that the recurrent inhibitory connections within the reticular nucleus may serve to desynchronize thalamic network activity (Huntsman et al., 1999). In thalamic circuits, both spindle-like and seizure-like oscillations depend on synaptic inhibition and rebound excitation (Kim et al., 1997; Ulrich and Huguenard, 1999). Thus, $\mathrm{GABA}_{\mathrm{A}}$ and $\mathrm{GABA}_{\mathrm{B}}$ receptordependent IPSPs in relay neurons promote oscillations (von Krosigk et al., 1993; Huguenard, 1999; Steriade, 2001; McCormick and Contreras, 2001). However, IPSPs in RT cells can have the opposite effect (Huntsman et al., 1999). The specific localization of functional NPY responses to RT cells would be antioscillatory and antiepileptic. Interestingly, TC cells have been shown to express high levels of functional $Y_{1}$ receptors (Sun et al., 2001a) and can generate hyperpolarizations because of GIRK current activation after exogenous NPY applications (Sun et al., 2001b). We speculate that the minimally detectable NPYergic sIPSPs in these cells (Fig. 4B3) might be caused by failure to release the peptide in sufficient quantities from RT neuron axon terminals in relay nuclei. In this connection, it is also important to mention the presence of dendrodendritic synapses as potential sites of NPY release in RT, but not VB (Pinault et al., 1995).

\section{Conditions for NPY release}

NPY mRNA is present in the majority of the perikarya in the reticular nucleus of the thalamus (Morris, 1989), suggesting that
GABAergic reticular neurons also synthesize NPY. Using confocal microscopy, we detected discrete NPY-positive fibers in the reticular nucleus (data not shown). Stimulation of corticothalamic fibers excites large numbers of RT neurons (von Krosigk et al., 1993; Huguenard, 1999), and we show here that this excitation results in presumed disynaptic sIPSPs mediated by endogenous NPY. A relatively high concentration of intraterminal calcium $(10-100 \mu \mathrm{M})$ may be required to trigger neuropeptide release (Lang et al., 1997; Ohnuma et al., 2001; Whim and Moss, 2001). Therefore, trains of high-frequency stimuli $(10-20 \mathrm{~Hz})$ that can result in large increases in $\mathrm{Ca}^{2+}$ within terminals (Zucker and Regehr, 2002) are effective in eliciting neuropeptide release in the CNS (Hökfelt, 2000; Weisskopf et al., 1993; Wagner et al., 1993; Kupfermann, 1991; Muschol and Salzberg, 2000). Our results agree with this suggestion and provide additional information regarding the conditions under which endogenous neuropeptides may be released. We show that graded sIPSCs could be evoked by increasing the number of stimulus trains within a group. A single stimulus train (four stimuli applied to the internal capsule at $25 \mathrm{~Hz}$ ) was apparently sufficient to release physiologically detectable levels of NPY.

The shortest latency from the onset of such stimuli to detectable actions of endogenous NPY was $\sim 200-400 \mathrm{msec}$ (Figs. 4A1, $5 A 2)$. Considering the rapid release of large dense core vesicles measured directly in some studies (2-4 msec) (Bruns et al., 2000; Whim and Moss, 2001), the time frame for NPY actions in RT is actually quite slow. Several mechanisms might account for this: (1) the release process might be much slower at nerve terminals than in neuroendocrine cells in which previous measurements have been made (Bruns et al., 2000; Whim and Moss, 2001); (2) release of peptide from neurons may require multiple steps including translocation of the large dense core vesicles (Burke et al., 1997); and (3) $Y_{1}$ receptors may be located distant from the release sites (Jan and Jan, 1982). Release of sufficient endogenous NPY to evoke sIPSCs normally required multiple trains applied at intervals of $300 \mathrm{msec}$. The significant enhancement of NPYergic postsynaptic actions by groups of stimulus trains (Fig. 6A) has not been reported in experiments on mammalian CNS neurons. In neuroendorine cells and non-neuronal tissues however, shortterm enhancement of neuropeptide release was apparent when two or more depolarizing pulses were given at various intervals from 60 to $100 \mathrm{msec}$ (Muschol and Salzberg, 2000; Whim and Moss, 2001).

\section{Physiological consequences of endogenous release of NPY}

Our data, obtained using intracellular recordings and synaptic stimulus trains that mimic repetitive burst firing in RT neurons, suggest that endogenously released NPY may modulate network oscillations in at least three ways. First, NPY released during a single synaptically evoked burst may provide negative feedback to limit the burst (data not shown). This could explain the observation that, during paroxysmal oscillations, the addition of BIBP3226 led to enhanced spiking (Fig. 8; Table 2). Second, $\mathrm{Y}_{1}$ receptors mediate a long-lasting sIPSP (duration, 2-10 sec) that may inhibit burst generation during a synchronized network oscillation. This seems to be the case, because BIBP3226 significantly increased the oscillation decay time constant by $46 \%$ and increased the number of bursts per oscillation by $26 \%$ (Fig. 8 ; Table 2). Third, persistently elevated NPY levels resulting from endogenous release could increase the resting membrane potentials of a large population of RT neurons, making it less likely that additional RT neurons would be recruited to generate propagat- 
ing spike-waves or spindle waves (McCormick and Contreras, 2001).

After blockade of endogenous $Y_{1}$ receptors, we found that trains of internal capsule stimuli evoked a slow membrane depolarization in RT cells (Fig. 7A2) that could trigger action potentials (data not shown). Such slow depolarizing potentials may be mediated via activation of metabotropic glutamate receptors (mGluRs) in RT cells (von Krosigk et al., 1993). We found that the duration of the slow depolarization was $\sim 200-300$ msec after a single synaptic train (data not shown) and 300-2000 msec after three to six trains, each containing four stimuli (Fig. 7A2). These response durations are similar to those reported previously for activation of mGluRs in the thalamus (von Krosigk et al., 1993; Golshani et al., 1998). In addition, preliminary results indicate that the slow depolarizations are blocked by mGluR1 antagonists (Sun et al., 2002b). Together, these findings indicate that both glutamatergic metabotropic excitation and NPYergic inhibition may occur simultaneously at postsynaptic sites on RT cells. We suggest that the balance between these two postsynaptic events is critically important in maintaining the timing and strength of burst discharges in RT neurons and network oscillations.

In our previous studies in the thalamus, we found that $\mathrm{Y}_{2}$ and $\mathrm{Y}_{1}$ receptors are functionally segregated at presynaptic and postsynaptic sites, respectively. However, the physiological roles of $\mathrm{Y}_{2}$ receptors activated by endogenously released NPY, from both recurrent collaterals within RT and feedforward synapses onto TC relay neurons in dorsal thalamus, are not yet known. Exogenous activation of $\mathrm{Y}_{2}$ receptors by a $\mathrm{Y}_{2}$ agonist (NPY3-36) resulted in a reduction of spontaneous and evoked GABA release but had no direct effect on RT neuron excitability (Sun et al., $2001 a, b)$. Because a selective antagonist for $\mathrm{Y}_{2}$ receptors is not generally available, the roles of these receptors, and their activation by endogenous release of NPY, cannot yet be tested. We speculate that $\mathrm{Y}_{2}$ receptors may also serve as autocrine sensors (i.e., when the extracellular NPY concentration is elevated, these receptors would be activated to inhibit additional release of NPY and GABA) (Sun et al., 2001b).

In summary, our results show that endogenous NPY can be released from GABAergic neurons of the RT cells under conditions in which repetitive burst responses are evoked in response to trains of stimuli (Fig. 1), or in the course of rhythmic, pathophysiological oscillations (Fig. 8). The released NPY exerts a direct postsynaptic inhibition (NPYergic IPSP) of RT neurons, but not target relay neurons, via activation of G-protein-coupled receptors and a potassium channel. Furthermore, NPY released endogenously by epileptiform network oscillations causes a selfsuppression of such activities in vitro.

\section{References}

Baraban SC, Hollopeter G, Erickson JC, Schwartzkroin PA, Palmiter RD (1997) Knock-out mice reveal a critical antiepileptic role for neuropeptide Y. J Neurosci 17:8927-8936.

Bruns D, Riedel D, Klingauf J, Jahn R (2000) Quantal release of serotonin. Neuron 28:205-220.

Burke NV, Han W, Li D, Takimoto K, Watkins SC, Levitan ES (1997) Neuronal peptide release is limited by secretory granule mobility. Neuron 19:1095-1102.

Chen C, Regehr WG (1999) Contributions of residual calcium to fast synaptic transmission. J Neurosci 19:6257-6266.

Chow RH, von Rüden L (1995) Electrochemical detection of secretion from single cells. In: Single channel recording, Ed 2 (Sakmann B, Neher E, eds), pp 245-272. New York: Plenum.

Cox CL, Huguenard JR, Prince DA (1997) Peptidergic modulation of intrathalamic circuit activity in vitro: actions of cholecystokinin. J Neurosci $17: 70-82$
Crunelli V, Leresche N (1991) A role for $\mathrm{GABA}_{\mathrm{B}}$ receptors in excitation and inhibition of thalamocortical cells. Trends Neurosci 14:16-21.

Debarbieux F, Brunton J, Charpak S (1998) Effect of bicuculline on thalamic activity: a direct blockade of IAHP in reticularis neurons. J Neurophysiol 79:2911-2918.

Doods HN, Wienen W, Entzeroth M, Rudolf K, Eberlein W, Engel W, Wieland HA (1995) Parmacological characterization of the selective nonpeptide neuropeptide Y Y1 receptor antagonist BIBP 3226. J Pharmacol Exp Ther 275:136-142.

Dutar P, Petrozzino JJ, Vu HM, Schmidt MF, Perkel DJ (2000) Slow synaptic inhibition mediated by metabotropic glutamate receptor activation of GIRK channels. J Neurophysiol 84:2284-2290.

Erickson JC, Clegg KE, Palmiter RD (1996) Sensitivity to leptin and susceptibility to seizures of mice lacking neuropeptide Y. Nature 381:415-421.

Golshani P, Warren RA, Jones EG (1998) Progression of change in NMDA, non-NMDA, and metabotropic glutamate receptor function at the developing corticothalamic synapse. J Neurophysiol 80:143-154.

Hökfelt T (1991) Neuropeptides in perspective: the last ten years. Neuron 7:867-879.

Hökfelt T, Broberger C, Xu ZD, Sergeyev V, Ubink R, Diez M (2000) Neuropeptides-an overview. Neuropharmacology 39:1337-1356.

Huguenard JR (1999) Neuronal circuitry of thalamocortical epilepsy and mechanisms of antiabsence drug action. Adv Neurol 79:991-999.

Huguenard JR, Prince DA (1994) Intrathalamic rhythmicity studied in vitro: nominal T-current modulation causes robust antioscillatory effects. J Neurosci 14:5485-5502.

Huntsman MM, Porcello DM, Homanics GE, DeLorey TM, Huguenard JR (1999) Reciprocal inhibitory connections and network synchrony in the mammalian thalamus. Science 283:541-543.

Jan LY, Jan YN (1982) Peptidergic transmission in sympathetic ganglia of the frog. J Physiol (Lond) 327:219-246.

Jan YN, Jan LY, Kuffler SW (1979) A peptide as a possible transmitter in sympathetic ganglia of the frog. Proc Natl Acad Sci USA 76:1501-1505.

Kim U, Sanchez-Vives MV, McCormick DA (1997) Functional dynamics of GABAergic inhibition in the thalamus. Science 278:130-134.

Kombian SB, Mouginot D, Pittman QJ (1997) Dendritically released peptides act as retrograde modulators of afferent excitation in the supraoptic nucleus in vitro. Neuron 19:903-912.

Kupfermann I (1991) Functional studies of cotransmission. Physiol Rev 71:683-732.

Lang T, Wacker I, Steyer J, Kaether C, Wunderlich I, Soldati T, Gerdes HH, Almers W (1997) $\mathrm{Ca}^{2+}$-triggered peptide secretion in single cells imaged with green fluorescent protein and evanescent-wave microscopy. Neuron 18:857-863.

Liu XB, Jones EG (1999) Predominance of corticothalamic synaptic inputs to thalamic reticular nucleus neurons in the rat. J Comp Neurol 414:67-79.

Luhmann HJ, Prince DA (1991) Postnatal maturation of the GABAergic system in rat neocortex. J Neurophysiol 65:247-263.

McCormick DA, Contreras D (2001) On the cellular and network bases of epileptic seizures. Annu Rev Physiol 63:815-846.

Miyata M, Okada D, Hashimoto K, Kano M, Ito M (1999) Corticotropinreleasing factor plays a permissive role in cerebellar long-term depression. Neuron 22:763-775.

Molinari M, Hendry SH, Jones EG (1987) Distributions of certain neuropeptides in the primate thalamus. Brain Res 26:270-289.

Morris BJ (1989) Neuronal localisation of neuropeptide Y gene expression in rat brain. J Comp Neurol 290:358-368.

Muschol M, Salzberg BM (2000) Dependence of transient and residual calcium dynamics on action-potential patterning during neuropeptide secretion. J Neurosci 20:6773-6780.

Nicoll RA (1978) The action of thyrotropin-releasing hormone, substance P and related peptides on frog spinal motoneurons. J Pharmacol Exp Ther 207:817-824.

Nusbaum MP, Blitz DM, Swensen AM, Wood D, Marder E (2001) The roles of co-transmission in neural network modulation. Trends Neurosci 234:146-154.

Ohnuma K, Whim MD, Fetter RD, Kaczmarek LK, Zucker RS (2001) Presynaptic target of $\mathrm{Ca}^{2+}$ action on neuropeptide and acetylcholine release in Aplysia californica. J Physiol (Lond) 535:647-662.

Pinault D, Bourassa J, Deschenes M (1995) The axonal arborization of sin- 
gle thalamic reticular neurons in the somatosensory thalamus of the rat. Eur J Neurosci 7:31-40.

Reyes A, Lujan R, Rozov A, Burnashev N, Somogyi P, Sakmann B (1998) Target-cell-specific facilitation and depression in neocortical circuits. Nat Neurosci 1:279-285.

Rozov A, Burnashev N, Sakmann B, Neher E (2001) Transmitter release modulation by intracellular $\mathrm{Ca}^{2+}$ buffers in facilitating and depressing nerve terminals of pyramidal cells in layer $2 / 3$ of the rat neocortex indicates a target cell-specific difference in presynaptic calcium dynamics. J Physiol (Lond) 531:807-826.

Scheibel ME, Scheibel AB (1966) The organization of the nucleus reticularis thalami: a Golgi study. Brain Res 1:43-62.

Sodickson DL, Bean BP (1996) $\mathrm{GABA}_{\mathrm{B}}$ receptor-activated inwardly rectifying potassium current in dissociated hippocampal CA3 neurons. J Neurosci 16:6374-6385.

Solis JM, Nicoll RA (1992) Pharmacological characterization of $\mathrm{GABA}_{\mathrm{B}}$ mediated responses in the $\mathrm{CA} 1$ region of the rat hippocampal slice. J Neurosci 12:3466-3472.

Soltesz I, Haby M, Leresche N, Crunelli V (1988) The $\mathrm{GABA}_{\mathrm{B}}$ antagonist phaclofen inhibits the late $\mathrm{K}^{+}$-dependent IPSP in cat and rat thalamic and hippocampal neurones. Brain Res 448:351-354.

Steriade M (2001) Impact of network activities on neuronal properties in corticothalamic systems. J Neurophysiol 86:1-39.

Strand FL (1999) Neuropeptide: regulation of physiological process. Cambridge, MA: MIT.

Sun QQ, Huguenard JR, Prince DA (2001a) Neuropeptide Y receptors differentially modulate $\mathrm{G}$-protein-activated inwardly rectifying $\mathrm{K}^{+}$channels and high-voltage-activated $\mathrm{Ca}^{2+}$ channels in rat thalamic neurons. J Physiol (Lond) 531:67-79.

Sun QQ, Akk G, Huguenard JR, Prince DA (2001b) Differential regulation of GABA release and neuronal excitability mediated by neuropeptide $Y_{1}$ and $\mathrm{Y}_{2}$ receptors in rat thalamic neurons. J Physiol (Lond) 531:81-94.

Sun QQ, Huguenard JR, Prince DA (2002a) Somatostatin inhibits thalamic network oscillations in vitro: actions on the GABAergic neurons of the reticular nucleus. J Neurosci 22:5374-5386.

Sun QQ, Bandrowski AE, Prince DA, Huguenard JR (2002b) Excitatory and inhibitory metabotropic postsynaptic responses in thalamic reticular neurons: glutamatergic and neuropeptide $\mathrm{Y}$-ergic mechanisms that regulate epileptiform thalamic network responses. Epilepsia 43: [Suppl 7]:118.

Thomson AM (2000) Facilitation, augmentation and potentiation at central synapses. Trends Neurosci 23:305-312.

Toth K, McBain CJ (2000) Target-specific expression of pre- and postsynaptic mechanisms. J Physiol (Lond) 525:41-51.

Ulrich D, Huguenard JR (1995) Purinergic inhibition of GABA and glutamate release in the thalamus: implications for thalamic network activity. Neuron 15:909-918.

Ulrich D, Huguenard JR (1999) $\mathrm{GABA}_{\mathrm{B}}$ receptor-mediated responses in GABAergic projection neurones of rat nucleus reticularis thalami in vitro. J Physiol (Lond) 493:845-854.

von Krosigk M, Bal T, McCormick DA (1993) Cellular mechanisms of a synchronized oscillation in the thalamus. Science 261:361-364.

Wagner JJ, Terman GW, Chavkin C (1993) Endogenous dynorphins inhibit excitatory neurotransmission and block LTP induction in the hippocampus. Nature 363:451-454.

Warren RA, Jones EG (1997) Maturation of neuronal form and function in a mouse thalamo-cortical circuit. J Neurosci 17:277-295.

Warren RA, Agmon A, Jones EG (1994) Oscillatory synaptic interactions between ventroposterior and reticular neurons in mouse thalamus in vitro. J. Neurophysiol 72:1993-2003.

Warren RA, Golshani P, Jones EG (1997) (1997) GABA $_{\mathrm{B}}$-receptormediated inhibition in developing mouse ventral posterior thalamic nucleus. J. Neurophysiol 78:550-553.

Weisskopf MG, Zalutsky RA, Nicoll RA (1993) The opioid peptide dynorphin mediates heterosynaptic depression of hippocampal mossy fibre synapses and modulates long-term potentiation. Nature 362:423-427.

Whim MD, Moss GW (2001) A novel technique that measures peptide secretion on a millisecond timescale reveals rapid changes in release. Neuron 30:37-50.

Zhang SJ, Huguenard JR, Prince DA (1997) $\mathrm{GABA}_{\mathrm{A}}$ receptor-mediated $\mathrm{Cl}^{-}$ currents in rat thalamic reticular and relay neurons. J Neurophysiol 78:2280-2286.

Zucker RS, Regehr WG (2002) Short-term synaptic plasticity. Annu Rev Physiol 64:355-405. 